\title{
A Rugged Null-Type Pressure Transducer of High Repro- ducibility for Accurate Gas Phase PVT Measurements
}

\author{
Meyer Waxman and William T. Chen
}

(July 31, 1964)

\begin{abstract}
A rugged and highly reproducible null-type transducer for accurately determining the equilibrium pressure between a Burnett PVT apparatus for gases and a counterbalancing pressure system is described. The transducer, closely coupled to the PVT sample volume, is used at temperatures from 0 to $175{ }^{\circ} \mathrm{C}$ and over the pressure range 4 to 250 atm. The transducer basicaliy consists of a metallic diaphragm as the pressure responsive element, a stable capacitance sensor for detecting minute deflections of the diaphragm, and spherical concave backing surfaces with a sagitta of $0.001 \mathrm{in}$. and a chord of $0.937 \mathrm{in}$. for supporting the diaphragm against excessive pressure imbalances. The diaphragm is 0.001 in. thick, plane and circular with an effective deflection diameter of 0.937 in., and prestressed to reduce appreciably inelastic factors. The reproducibility of the null after the transducer has been subjected to unidirectional pressure overloads as large as $135 \mathrm{~atm}$ is within \pm 0.1 $\mathrm{mm} \mathrm{Hg}$. For pressure imbalances less than $1 \mathrm{~atm}$ and transducer pressures of $1 \mathrm{~atm}$ or less, the reproducibility is within $9 \times 10^{-3} \mathrm{~mm} \mathrm{Hg}$, which is the equivalent resolution of the capacitance circuitry. The maximum uncertainty in the null for transducer pressures varying from 4 to $250 \mathrm{~atm}$ is, respectively, 0.003 to 0.00004 percent. The maximum uncertainty in the constancy of the transducer volume is $7 \times 10^{-5} \mathrm{~cm}^{3}$ and contributes a maximum error of 0.0003 percent in the constancy of the sample PVT volume. General requirements, design considerations, and factors which limit the reproducibility of the transducer null are discussed. Detailed performance data at $25{ }^{\circ} \mathrm{C}$ are given.
\end{abstract}

\section{Introduction}

In an experimental PV'T program for corrosive gases being conducted at the National Bureau of Standards, the coupling of the sample volume to the pressure-measuring instrumentation presented several problems. Ideally, the coupling should not affect the accuracy of the pressure measurements and should confine the gas to the sample volume. Correcting for the effect of extraneous volumes introduced through the coupling is difficult, and can result in significant errors, particularly if the temperatures of the extraneous volumes are lower than the temperature of the sample volume. In addition, the corrosive nature of the gases makes it desirable to isolate the gas from the pressure-measuring instrumentation so as to prevent possible chemical reaction of the gas with materials usually used in pressure gages. These general requirements suggested the use of a null-type transducer closely coupled to the sample volume and utilizing a circular plane or corrugated diaphragm as the gas separator and also as the pressure-responsive element $[1,2,3]{ }^{1}$ If the transducer is thermostated at the temperature of the sample volume, the extraneous volume introduced, particularly if small, should have a negligible effect on the evaluation and constancy of the sample volume.

In the projected application of the transducer, the pressure of the sample gas acting on one side of the diaphragm is counterbalanced by an auxiliary gas

${ }^{*}$ This work was supported in part by the Division of Research, Atomic Energy Commission.

Figures in brackets indicate the literature references at the end of this paper system whose pressure is measured by a piston gage or a manometer. A pressure imbalance across the diaphragm deflects it, and this deflection is detected on the counterbalancing side of the diaphragm by an electrical capacitance method.

The first application of the transducer was to be in a Burnett apparatus [4] which imposed additional requirements. Through this apparatus, isotherms are derived for experimental pressures from 4 to $250 \mathrm{~atm}$ and over the temperature range 0 to $175^{\circ} \mathrm{C}$. The required precision of the pressure measurements was 1 part in 30,000 , which is equivalent to $0.1 \mathrm{~mm} \mathrm{Hg}$ for a gage pressure of $3 \mathrm{~atm}$. The Burnett procedure consists of an iterative process of expanding the gas from a sample chamber into a previously evacuated auxiliary chamber. Pressure measurements are made before and after each expansion with a suitable time allowance for equilibration. If a diaphragm with the required sensitivity is used, the step-wise expansion results in a pressure imbalance many times greater than the elasticpressure range of the diaphragm, whether plane or corrugated. Thus, the deflection of the diaphragm has to be limited, as excessive pressure imbalances would stretch it beyond its elastic limit, resulting in rupture or adverse effects on the reproducibility of the diaphragm null position.

At the time this problem was being considered, a survey of the available literature did not disclose a design or instrument that would satisfy the requirements discussed above. Thus the design of transducer prototypes was considered for both the plane and corrugated types of diaphragm transducer. 
The reproducibility of the diaphragm null position for both types is affected by the elasticity of the diaphragm material and the stress anisotropy in the diaphragm. In the plane diaphragm, localized stresses or buckled areas can result in snap-action characteristics ("oil-canning") of the diaphragm, that is, with a changing pressure, the diaphragm has a sudden and discontinuous change of deflection. The shape, magnitude, and pressure characteristics associated with this deflection may vary considerably. Stress anisotropy can originate in the blank material or develop when the plane diaphragm is clamped to effect its pressure seal. The adverse effects of this anisotropy on performance can be eliminated or reduced appreciably by radial prestressing of the diaphragm. In the corrugated diaphragm, stress anisotropy in the blank material is eliminated in the forming and heat treatment process, and that introduced from the clamping process has generally a negligible effect on the performance of the diaphragm.

For the corrugated type of diaphragm, its protection against excessive pressure imbalances (overload protection) can be accomplished in one direction with the die used in forming the diaphragm as a backing plate. The fabrication of a backing plate for the opposite direction is considered to be difficult but not insurmountable. For the plane type of diaphragm, spherical concave backing plates can be fabrieated to the approximate configuration of the diaphragm for a specified deflection [5]. A capacitance sensor for detecting minute deflections of the diaphragm can be fabricated as part of the backing plate for both types [5].

In addition to the overload protection feature, other important design considerations are the pressure-deflection characteristics, particularly the sensitivity at the diaphragm null position, and the elasticpressure range. In a plane diaphragm with its edge completely fixed, the pressure-deflection characteristics depend on the magnitude of the radial prestressing. If the prestressing and the central deflections are small, the pressure-deflection relationship is that of a thin disk with the effect of prestressing included [6]. If the prestressing is increased sufficiently, however, the bending stress in the diaphragm becomes negligible relative to the applied radial stress, and the diaphragm characteristics can be considered as approximating those of a membrane. The pressuredeflection characteristics of the corrugated type of diaphragm have been evaluated in terms of the mechanical properties of the diaphragm material, its thickness, and its geometry, such as the spacing, depth, and number of convolutions $[7,8]$. For small deflections of either type of diaphragm fabricated from the same material and having the same thickness and free diameter, the maximum sensitivity obtainable is greater for the plane type than it is for the corrugated type.

The development of transducer prototypes had as its objective the attainment of an easily fabricated design that satisfied the specified requirements. Because of previous experience with the plane type, it

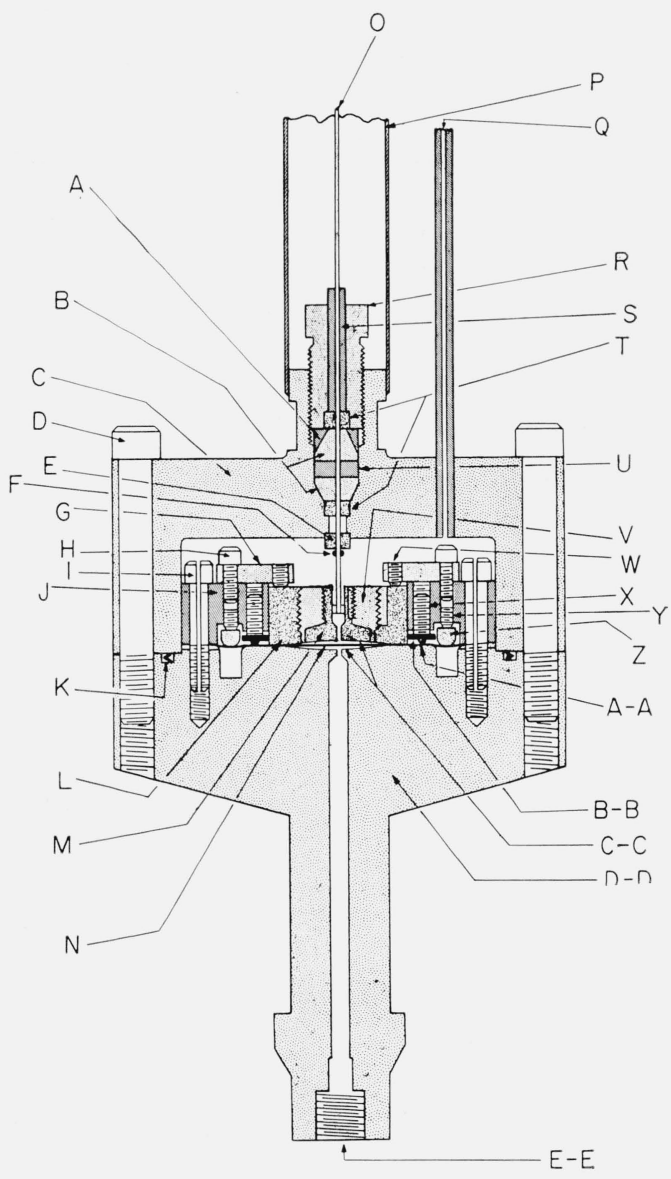

Figure 1. Cross section of transducer model II.
A. Follower, steel
B. Extrusion rings, lava stone
C. Top, nickel
D. Clamping bolts for pressure seal $\mathrm{K}$
E. Ring, ceramic
F. Electrode stop, silver brazed bead
G. Clamping ring for capacitance sensor assembly, nickel
$H$. Inner clamping screws for Inner clamping
I. Outer clamping screws for clamping ring J
J. Clamping ring
K. V-ring, Teflon-coated Monel
L. Capacitor housing, nickel
M. Capacitor plate, nickel
N. Diaphragm, Mone
o. Capacitor lead, drill rod
$\mathrm{P}$. Electrical and oil shield, Monel

Q. Counterbalancing gas inlet tube, nickel

R. Packing gland nut, stee]

S. Electrical insulating sleeve,Teflon

$\mathrm{T}$. Extrusion rings, ceramic

U. Packing ring, Teflon

V. Epoxy cement (insulator)

W. Thrust serews for clamping capacitance sensor assembly

$\mathrm{X}$. Thrust screws for diaphragm pressure seal A-A

pressure seal A-A
$Y$. Thrust screws for stressing diaphragm N

Z. Stressing ring, nickel

A-A. Diaphragm seal height-0.003 in., tool steel$50 \mathrm{RC}$

C-C. Diaphragm backing surface

D-D. Base

E-E. Sample gas port

was selected for the basic design of the transducer. Two models based on this design were fabricated. The second model, II, is shown in figure 1 with exploded views in figures 2,3 , and 4 . In the first and earlier model, preferred initially for its smaller o.d., the pressure characteristics satisfied the requirements; however, the pressure seals were not effective over the required temperature range of 0 to $175^{\circ} \mathrm{C}$. The second model, fabricated after the first was thoroughly tested, was comparatively easier to fabricate and to seal effectively. This model has proven to be quite satisfactory and it is currently being used. 


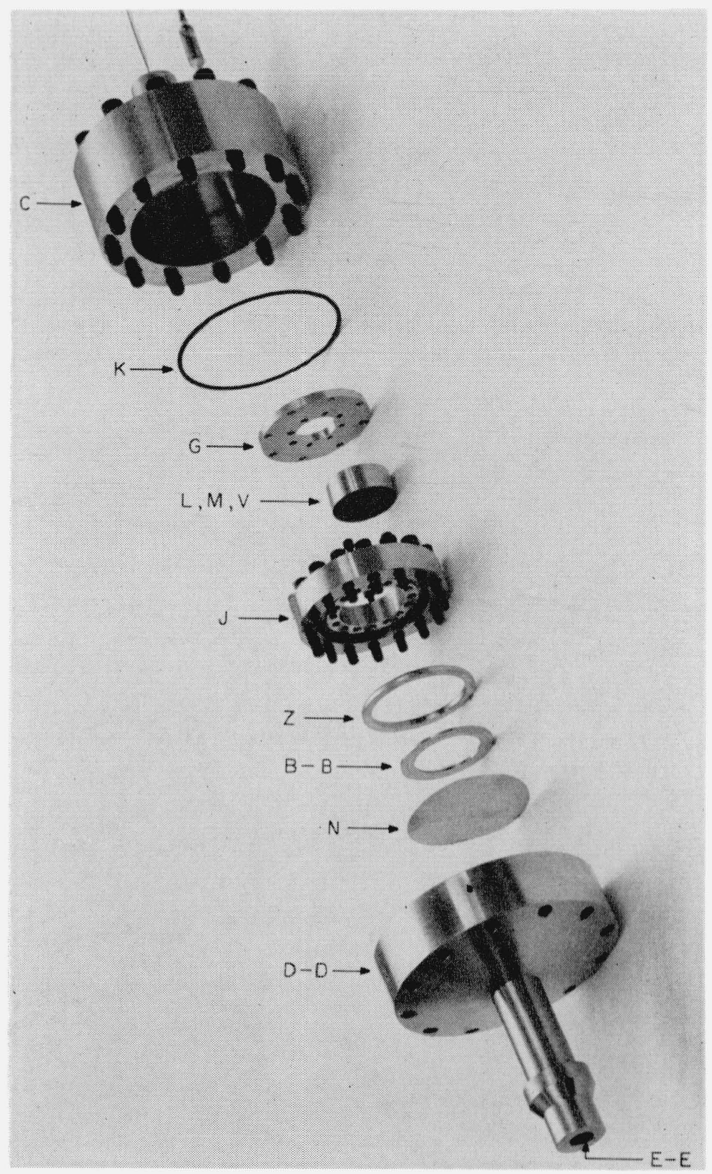

Figure 2. Exploded view of transducer. See figure 1 legend.

\section{Description and Installation of Components}

\subsection{Transducer}

The model II transducer (see fig. 1) basically consists of the prestressed diaphragm $\mathrm{N}$ as the pressure responsive element, the capacitance sensor assembly (L, M, and V) for detecting deflections of the diaphragm, and the diaphragm backing surfaces C-C incorporated as part both of the base D-D and of the capacitance sensor assembly. This assembly is clamped in position by the use of the thrust screws $\mathrm{W}$ and the clamping ring $\mathrm{G}$, which is first clamped to the clamping ring $\mathbf{J}$ by means of the inner clamping screws $H$. The clamping force exerted on this latter clamping ring $(J)$ through the tightening of the outer clamping screws $\mathrm{I}$ is considerably greater than that of the total opposing thrust forces developed in stressing the diaphragm, effecting the diaphragm pressure seal, and clamping the capacitance sensor assembly. The base and the top $\mathrm{C}$ clamped together through the use of the clamping bolts $\mathrm{D}$ constitute the pressure housing which is designed to withstand pressures up to $500 \mathrm{~atm}$ without excessive deformation. The external pressure seals consist of the

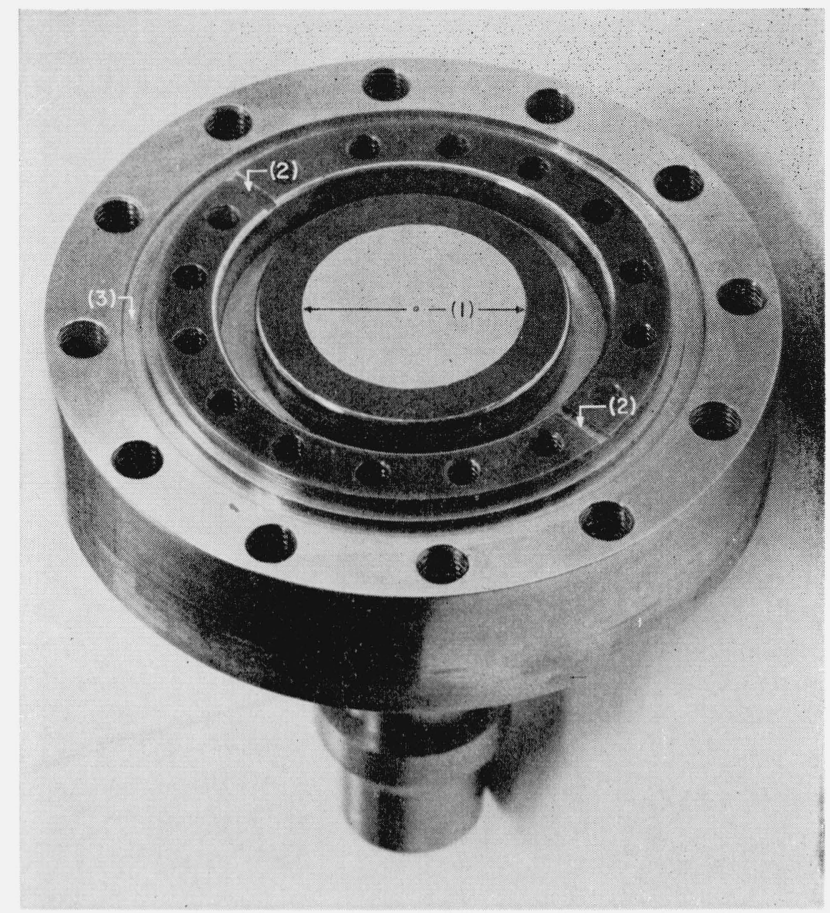

Figure 3. Base of transducer showing (1) spherical concave backing surface, (2) grooves to facilitate pressure equilibrium, and (3) groove for the v-ring pressure seal.

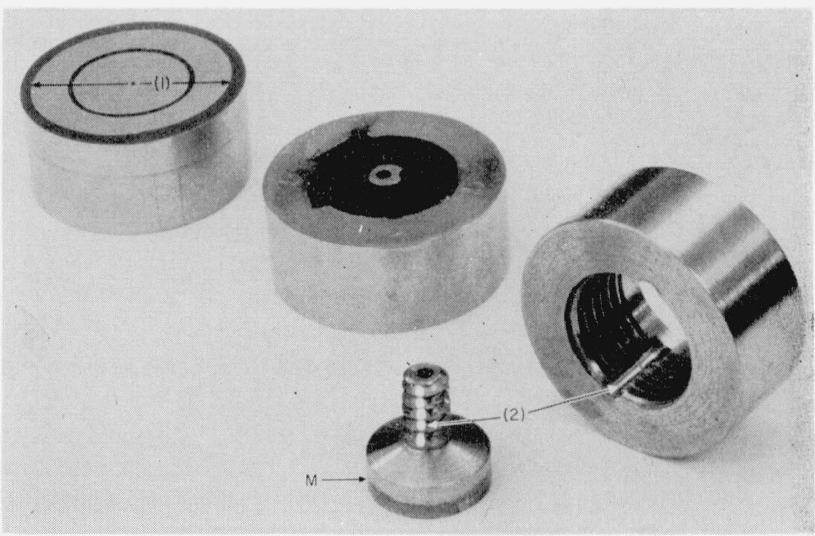

FIgURE 4. Three views of capacitance sensor assembly ( $L, M$, $V)$ showing (1) spherical concave backing surface, and (2) threaded and slotted bonding surfaces to enhance the mechanical support of the capacitor plate.

v-ring $\mathrm{K}$ clamped between the top and the base, and the Teflon packing ring $\mathrm{U}$ which is compressed for sealing the capacitor lead O. The lower reduced section of the base is designed for coupling the transducer to a Burnett apparatus [4]. The sample gas inlet is through the port E-E to the bottom side of the diaphragm, and the counterbalancing gas inlet is through the tube $\mathrm{Q}$ to the top side of the diaphragm. To facilitate the equilibrium of gas pressure on the top side, there is an axial hole in each of the outer clamping screws and two grooves 
between the v-ring circular groove and the circular groove beneath the stressing ring (see fig. 3). Most of the transducer components are fabricated from commercial grade A nickel to resist gas corrosion.

\subsection{Capacitance Sensor Āssembly and Detector}

A deflection of the diaphragm is detected electrically by a corresponding change of the capacitance between the capacitor plate $\mathrm{M}$ and the diaphragm (see fig. 1). The capacitor plate is electrically insulated and mechanically supported by the epoxy cement $V$ between the capacitor plate and the capacitor housing L. This capacitance sensor assembly is positioned and clamped after the diaphragm has been installed.

The capacitance sensor assembly is designed so that it is fabricated easily and yet provides adequate mechanical support for the capacitor plate without introducing an excessive residual capacitance. The mechanical support is derived primarily from (1) the strength of the adhesive bond between the epoxy cement and the metallic components and (2) the shear strength of the epoxy cement in the threaded and slotted regions of the capacitor plate and the capacitor housing (see fig. 4). The adhesive bond alone is not sufficient to provide the necessary mechanical support. The threads and slots provide, respectively, translational and rotational support of the capacitor plate. The latter support is necessary for the final lathe machining of the assembly. The epoxy cement retains its physical stability up to $225{ }^{\circ} \mathrm{C}$ and has a temperature coefficient of expansion of $15 \times 10^{-6}$ per ${ }^{\circ} \mathrm{C}$, comparable to that of the capacitor housing and capacitor plate fabricated from nickel. The residual capacitance of this assembly is $10 \mathrm{pF}$.

The transducer capacitance, consisting of the residual capacitance and that between the capacitor plate and the diaphragm, constitutes one arm of a capacitance bridge. The bridge also has a variable capacitance arm, and two large and nearly equal capacitance ratio arms. The capacitor plate is coupled via the capacitor lead to a double shielded coaxial cable connected to the bridge. The effect of variations in cable capacitance on the bridge balance is reduced appreciably by shunting the capacitance between the inner shield and the central lead across a ratio capacitor. The capacitance between the inner shield and the outer shield at ground potential is shunted across the output of the bridge, and variations in it affect only slightly the sensitivity of the bridge circuit. A deflection of the diaphragm unbalances the capacitance bridge. The unbalanced signal is amplified, phase detected, and indicated on a 100-0-100 microammeter. The capacitance stability of the bridge circuitry exclusive of the transducer is $0.03 \mathrm{pF}$, which is the minimum change of capacitance detectable with the bridge voltage $(0.4 \mathrm{~V})$ and the amplification being used. The potential difference between the diaphragm and the capacitor plate is sufficiently small for the effect of the associated electrostatic attraction to be negligible in the performance of the transducer.

\subsection{Diaphragm Backing Surfaces}

Diaphragm displacement is limited on each side by both the plane and spherical concave backing surfaces which were optically lapped. The nominal values of the sagitta and the chord of the spherical concave backing surface are $0.001 \mathrm{in}$. and $0.937 \mathrm{in.}$ respectively (the corresponding radius of curvature is $9.2 \mathrm{ft}$ ). This chord is the effective diameter of the diaphragm area in which deflections can occur. The 0.001 in. central separation results in a capacitance of $49 \mathrm{pF}$ between the capacitor plate and the diaphragm. Closer spacing may cause electrical shorting of the capacitor plate since minute dimples develop in the diaphragm after some usage. For pressure imbalances greater than the equivalent of $0.001 \mathrm{in}$. central deflection of the diaphragm, the diaphragm is supported by a backing surface and the diaphragm stresses remain within the elastic limits. The magnitude of permissible pressure imbalance is governed by both the rigidity of the backing surfaces and the stress developed in the unsupported sector of the diaphragm (central 0.014 in. diameter) when it is deflected against a backing surface. The pressure imbalance which the capacitor plate will support without affecting significantly the transducer performance is generally limited to $5 \mathrm{~atm}$, although it has been exceeded a few times by a factor of 3 to 8 . The pressure imbalance applied against the base can be considerably greater and has at times been as great as $135 \mathrm{~atm}$.

\subsection{Pressure Seals}

In model I, the seal consisting of a toroidal copper ring clamped between the top and the base leaked above $150{ }^{\circ} \mathrm{C}$, even though considerable clamping force was exerted on the ring. The difference in the temperature coefficient of expansion between the metals of the seal or the plastic flow of the copper ring may have been the cause for the leakage. In model II, a commercial Teflon-coated Monel v-ring $(\mathrm{K})$ replaces the copper ring and has proven to be very satisfactory. The transducer can be disassembled and assembled many times and the same seal is still effective for the operating range of pressures and temperatures. In the application of the v-type of seal, the v-ring is compressed slightly by the clamping of the base to the top to produce a line-contact with both surfaces bearing on it. The sealing process is then enhanced by the internal pressure acting against the inner surface of the v-ring.

The diaphragm seal $\mathrm{A}-\mathrm{A}$ which isolates the sample gas from the counterbalancing gas is effected by the thrust of the diaphragm sealing ring $\mathrm{B}-\mathrm{B}$ against the diaphragm and the base. This thrust, obtained by tightening thrust screws X, must be sufficient to deform either the sealing surface of the diaphragm or that of the base. The method used for testing this seal is to overpressure the transducer on the top side and check for gas leakage on the bottom side by means of an accumulative technique with a commercial leak detector. 
Different commercial seals basically similar to the seal used in model II (fig. 1, A, B, T, U) were tried for the capacitor lead seal. Generally these leaked when either Teflon or lava stone was used as the packing material. Teflon is more effective than lava stone for sealing in this type of seal; however, the Teflon must be supported completely. If a minute unsupported area exists, the Teflon extrudes through this area at about $150{ }^{\circ} \mathrm{C}$ for the maximum operating pressures. In the capacitor lead seal (model II), the Teflon packing ring is backed completely by lava stone extrusion rings $\mathrm{B}$, and these in turn are backed by ceramic extrusion rings $\mathrm{T}$. There is a clearance of about $\pm 0.002 \mathrm{in}$. on the o.d. and i.d. of the ceramic extrusion rings. A slight tightening of the packing gland nut $\mathrm{R}$ which bears against this sealing assembly is sufficient to obtain a seal. A bead F, silver brazed on the capacitor lead, and bearing against the ceramic ring E, acts as a stop for the capacitor lead and prevents it from being blown out.

\subsection{Installation of the Diaphragm}

Initially, the subassembly consisting of the clamping ring (J), stressing ring $Z$, diaphragm sealing ring $(\mathrm{B}-\mathrm{B})$, and the diaphragm $(\mathrm{N})$, is positioned concentric with the axis of the base (D-D) after which the clamping ring $(\mathbf{J})$ is clamped firmly to the base. This clamping adequately holds the edge of the diaphragm between the clamping ring and the base, and allows for radial stressing of the diaphragm without slippage at the outer edge. The stressing, accomplished by tightening the thrust screws $Y$ against the stressing ring (which in turn exerts a thrust on an annulus of the diaphragm), draws the diaphragm downward over the rounded corners of the groove beneath the stressing ring. The thrust screws (consisting of eight 4-40 cap set screws) require only a very gentle torque to provide the necessary stressing thrust.

Before effecting the diaphragm seal, the diaphragm is stressed slightly by tightening all the thrust screws to remove generalized distortions. Localized distortions are usually eliminated by the additional tightening of the appropriate thrust screws. Distorted sectors can readily be detected from any movement caused by gentle pressure on the diaphragm at small selected areas over the plane part of the backing surface. Clamping of the diaphragm to effect its seal generally results in severe distortion of the diaphragm, particularly if slight distortions already exist in the diaphragm blank. These distortions are eliminated, or the subsequent adverse effects are reduced appreciably, by gradually and intermittently increasing the clamping pressure and adjusting the diaphragm stress on a selected area basis. This method results in a highly reproducible null position of the diaphragm and eliminates the adverse effects discussed in section 1 .

\subsection{Fabrication of the Diaphragm}

The diaphragm, $1.90 \mathrm{in}$. in diameter and $0.001 \mathrm{in}$. thick, is fabricated from rolled Monel sheet stock, 0.001 in. thick and 4 in. wide. Different fabricating techniques, such as cutting with scissors, punching, and lathe machining, were tried. Of these, the machining technique developed fewer distortions in the diaphragm and proved most expedient. Several diaphragms should be prepared at one time. In this operation, about 20 square blanks separated from each other by 0.004 in. thick paper, and clamped together between expendable pressure plates mounted in a lathe, are machined to the required diameter. Approximately 25 percent of each lot is thus obtained relatively free of dimples or distorted areas and is therefore acceptable as diaphragms.

\section{Performance}

Early in the experimental use of the transducer there was concern with hysteresis of the diaphragm or other effects such as "oil-canning" which could affect the null position of the diaphragm. This problem is circumvented by confining any pressure overloading greater than a few atmospheres to the direction of the base, and overloading slightly the diaphragm towards the base prior to the final balancing of the gas pressures on both sides of the diaphragm. This procedure of using the unidirectional pressure behavior of the diaphragm eliminates or reduces appreciably the effect of bidirectional differences, if any, on the null position of the diaphragm.

Since the magnitude of the radial prestressing of the diaphragm varies from one diaphragm installation to another, the associated pressure imbalance versus bridge imbalance characteristics will vary also. In figure 5, a pressure imbalance versus $\Delta$ (bridge balance) graph, obtained at $25^{\circ} \mathrm{C}$ and $1 \mathrm{~atm}$, is shown for each of two diaphragm installations, one having the maximum sensitivity (diaphragm 1) and the other, the minimum sensitivity (diaphragm 2) encountered to date. By means of these graphs and a $0.03 \mathrm{pF}$ capacitance bridge resolution, the transducer resolution for the null condition is $9 \times 10^{-3}$ and $3 \times 10^{-3} \mathrm{~mm} \mathrm{Hg}$, respectively, for diaphragms 1 and 2. This resolution is equivalent to an average diaphragm deflection over the capacitor plate of $5 \times 10^{-7} \mathrm{in} .\left(1 \times 10^{-5} \mathrm{~mm}\right)$. The pressure range for which the deflection of the diaphragm is not restrained by either of the backing surfaces is generally about $\pm 1 \mathrm{~cm} \mathrm{Hg}$. This range is sufficient to counterbalance conveniently and accurately the sample gas pressure for pressures up to 250 atm [4].

The transducer null is affected by temperature and pressure changes. Experiments, in a special test rig, independent of the transducer indicated that this effect manifests itself primarily as a positional change of the capacitor plate relative to the diaphragm. It was found that a temperature change from 22 to $110{ }^{\circ} \mathrm{C}$ would change the transducer 


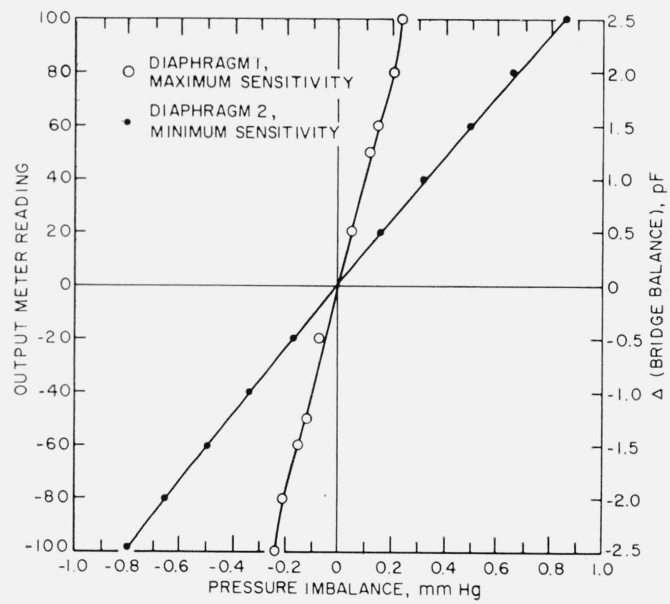

Figure-5. Pressure-deflection characteristics of the transducer (obtained at $25^{\circ} \mathrm{C}$ and 1 atm).

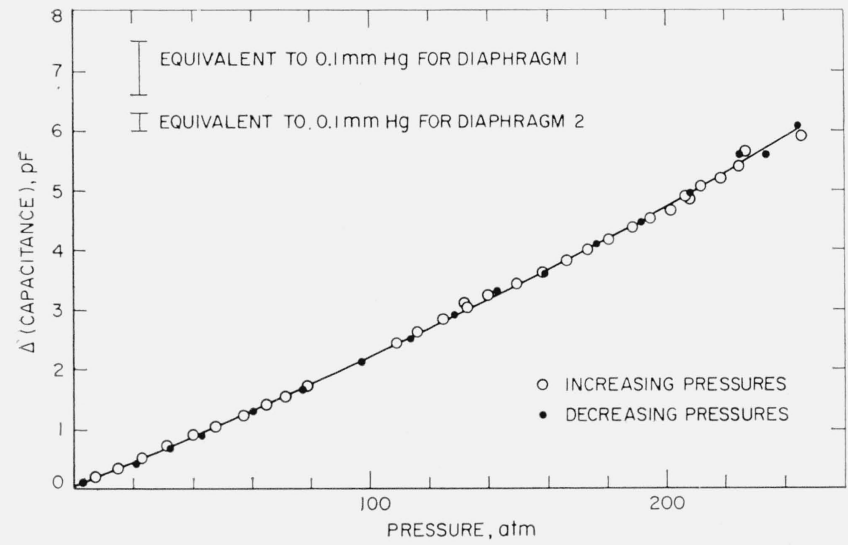

Frgure 6. Pressure effect on transducer capacitance for null condition (obtained at $25^{\circ} \mathrm{C}$ )

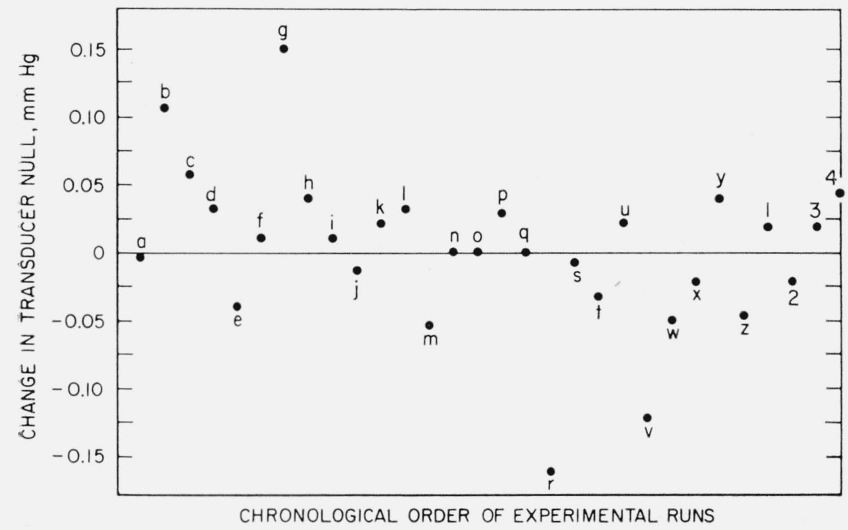

Figure 7. Stability of transducer null (obtained at $25{ }^{\circ} \mathrm{C}$ and $1 \mathrm{~atm})$.

See table 1 for identification of the points. null at 1 atm by the equivalent of $1.4 \mathrm{pF}$. For an isothermal application as mentioned in section 1 , the temperature variation is within $\pm 0.01{ }^{\circ} \mathrm{C}$ and results in a maximum pressure error of $5 \times 10^{-5} \mathrm{~mm}$ $\mathrm{Hg}$. This variation is smaller by a factor of two hundred than the detectable minimum pressure imbalance. An investigation of the pressure effect from 22 to $200{ }^{\circ} \mathrm{C}$ indicated that this effect can be determined to within $\pm 0.1 \mathrm{~mm} \mathrm{Ho}$. Pressure effects on the transducer null are compensated by changing the bridge balance according to a typical calibration graph (obtained at $25^{\circ} \mathrm{C}$ ) as shown in figure 6 . This graph was obtained with both sides of the transducer connected to a common gas source.

In the experimental procedure used with the Burnett apparatus, the transducer null at $1 \mathrm{~atm}$ is checked after the completion of the lower pressure measurements at the end of an experimental run. Stability test results (obtained at $25^{\circ} \mathrm{C}$ ), accumulated over a period of 4 months for different gases on the sample side of the diaphragm, are shown in figure 7 . The changes can be attributed to pressure overloading, which may change the null positions of both the diaphragm and the capacitor plate. The occasional changes outside of the range $\pm 0.1 \mathrm{~mm}$ $\mathrm{Hg}$ may be the result of excessive pressure imbalance against the capacitance sensor assembly. For present pressure measurements below $15 \mathrm{~atm}$, the measurements are corrected for the pressure change in the transducer null obtained after the completion of an experimental run, when this change is greater

TABLE 1. Experimental runs showing data used for points in figure $y$

\begin{tabular}{|c|c|c|c|}
\hline Point & $\begin{array}{c}\text { Maximum } \\
\text { transducer } \\
\text { pressure }\end{array}$ & $\begin{array}{l}\text { Maximum } \\
\text { pressure im- } \\
\text { balance against } \\
\text { the base }\end{array}$ & $\underset{\text { gas }}{\text { Sample }}$ \\
\hline $\begin{array}{l}\mathrm{a} \\
\mathrm{b} \\
\mathrm{c} \\
\mathrm{d} \\
\mathrm{e}\end{array}$ & $\begin{array}{r}\text { atm } \\
46 \\
136 \\
36 \\
186 \\
190\end{array}$ & $\begin{array}{r}\text { atm } \\
21 \\
57 \\
15 \\
82 \\
82\end{array}$ & $\begin{array}{l}\mathrm{He} \\
\mathrm{Ar} \\
\mathrm{He} \\
\mathrm{Ar} \\
\mathrm{Ar}\end{array}$ \\
\hline $\begin{array}{l}\mathrm{f} \\
\mathrm{g} \\
\mathrm{h} \\
\mathrm{i} \\
\mathrm{j}\end{array}$ & $\begin{array}{l}238 \\
235 \\
208 \\
207 \\
216\end{array}$ & $\begin{array}{r}105 \\
107 \\
94 \\
82 \\
100\end{array}$ & $\begin{array}{l}\mathrm{Ar} \\
\mathrm{He} \\
\mathrm{He} \\
\mathrm{He} \\
\mathrm{He}\end{array}$ \\
\hline $\begin{array}{l}\mathrm{k} \\
\mathrm{l} \\
\mathrm{m} \\
\mathrm{n} \\
\mathrm{o}\end{array}$ & $\begin{array}{l}158 \\
235 \\
238 \\
207 \\
170\end{array}$ & $\begin{array}{r}71 \\
\left({ }^{*}\right) \\
105 \\
88 \\
73\end{array}$ & $\begin{array}{l}\mathrm{He} \\
\mathrm{Ar} \\
\mathrm{Ar} \\
\mathrm{Ar} \\
\mathrm{Ar}\end{array}$ \\
\hline $\begin{array}{l}\mathrm{p} \\
\mathrm{q} \\
\mathrm{r} \\
\mathrm{s} \\
\mathrm{t}\end{array}$ & $\begin{array}{r}47 \\
200 \\
232 \\
173 \\
46\end{array}$ & $\begin{array}{r}21 \\
100 \\
129 \\
75 \\
21\end{array}$ & $\begin{array}{l}\mathrm{He} \\
\mathrm{BF}_{3} \\
\mathrm{BF}_{3} \\
\mathrm{BF}_{3} \\
\mathrm{He}\end{array}$ \\
\hline $\begin{array}{l}\mathrm{u} \\
\mathrm{v} \\
\mathrm{w} \\
\mathrm{x} \\
\mathrm{y}\end{array}$ & $\begin{array}{r}47 \\
144 \\
120 \\
130 \\
214\end{array}$ & $\begin{array}{r}21 \\
54 \\
38 \\
45 \\
113\end{array}$ & $\begin{array}{l}\mathrm{He} \\
\mathrm{BF}_{3} \\
\mathrm{BF}_{3} \\
\mathrm{BF}_{3} \\
\mathrm{BF}_{3}\end{array}$ \\
\hline $\begin{array}{l}\mathrm{z} \\
1 \\
2 \\
3 \\
4\end{array}$ & $\begin{array}{r}125 \\
157 \\
190 \\
27 \\
27\end{array}$ & $\begin{array}{l}41 \\
34 \\
64 \\
12 \\
12\end{array}$ & $\begin{array}{l}\mathrm{BF}_{3} \\
\mathrm{BF}_{3} \\
\mathrm{BF}_{3} \\
\mathrm{He} \\
\mathrm{He}\end{array}$ \\
\hline
\end{tabular}

*run discontinued. 
than 0.0014 percent. For pressure measurements above $15 \mathrm{~atm}$, this correction is not made as its effect in the Burnett method becomes small compared to other errors.

Some experimental pressure measurements with the transducer have been made at or below $1 \mathrm{~atm}$. At the completion of these measurements, the transducer null at $1 \mathrm{~atm}$ was checked and the offset from the null was found to be of the same magnitude as the equivalent resolution of the capacitance bridge (about the equivalent of $9 \times 10^{-3} \mathrm{~mm} \mathrm{Hg}$ ).

The volume enclosed by the diaphragm and the spherical concave backing surface of the base is part of the sample volume [4]. Therefore, an uncertainty in the diaphragm null position must be considered as it affects the constancy of the sample volume. The volume of either concave enclosure is 0.006 $\mathrm{cm}^{3}$ which, in the Burnett apparatus, represents 0.02 percent of the sample volume. An uncertainty in the diaphragm null position equivalent to $0.1 \mathrm{~mm}$ $\mathrm{Hg}$ would change the enclosure volume by a maximum of $7 \times 10^{-5} \mathrm{~cm}^{3}$, or about 0.0003 percent of the sample volume. In the Burnett method [4] the effect of this volume uncertainty is negligible compared to that of errors in the pressure measurements obtained with the piston gage.

The authors express their appreciation to Philomain Dery and Hans Mend for their skilled fabrication of the instrument and to Miss P. Naecker for her editorial advice.

\section{References}

[1] E. S. Burnett, Compressibility determinations without volume measurements, J. App. Mech. 58, A136-140 (1936)

[2] D. White and J. Hilsenrath, Pressure-sensitive diaphragm type null detector, Rev. Sci. Instr. 29, 648-651 (1958).

[3] A. Michels, T. Wassenaar, and Th. N. Zwietering, The experimental determination of the equation of state data of gases at temperatures between $0^{\circ} \mathrm{C}$ and -180 ${ }^{\circ} \mathrm{C}$, Physica XVIII, No. 1, 67-74 (1952).

[4] M. Waxman, W. T. Chen, and J. Hilsenrath, A Burnett apparatus for compressibility measurements on corrosive gases for pressures to $240 \mathrm{~atm}$ and temperatures from 0 to $175^{\circ} \mathrm{C}$ (to be published).

[5] H. F. Stimson, Precision Resistance Thermometry and Fixed Points, American Institute of Physics, Temperature, Its Measurement and Control in Science and Industry (Reinhold Publishing Corporation, New York, 1955), Vol. II, 166-167.

[6] A. A. Griffin, The theory of pressure capsules, British A. R. C., R and M No. 1136 (1927).

[7] W. A. Wildhack, R. F. Dressler, and E. C. Lloyd, Inves. tigations of the properties of corrugated diaphragms, Trans. Am. Soc. Mech. Engrs. 79, 65-82 (1957).

[8] F. B. Newell, Diaphragm Characteristics, Design and Terminology (ASME, New York, 1958). 